\title{
RESEARCH ON A MAGNETIC FIELD SENSOR WITH A FREQUENCY OUTPUT SIGNAL BASED ON A TUNNEL-RESONANCE DIODE
}

\author{
Alexander V. Osadchuk, Vladimir S. Osadchuk, Iaroslav A. Osadchuk \\ Vinnytsia National Technical University, Faculty of Information Communication, Radio Electronics and Nanosystems. \\ Abstract. Based on the consideration of physical processes in a tunnel-resonant diode under the action of a magnetic field, the construction of an \\ autogenerating magnetic field sensor with a frequency output signal is proposed. The use of devices with negative differential resistance makes it possible \\ to significantly simplify the design of magnetic field sensors in the entire RF frequency range. Depending on the operating modes of the sensor, an output \\ signal can be obtained in the form of harmonic oscillations, as well as in the form of pulse oscillations of a special form. \\ The study of the characteristics of the magnetic field sensor is based on the complete equivalent circuit of the tunnel-resonant diode. The equivalent circuit \\ takes into account both the capacitive and inductive properties of the tunneling resonant diode. The inductive component exists under any operating \\ conditions, as a result of the fact that the current flowing through the device is always lagging behind the voltage that caused it, which corresponds to the \\ inductive response of a tunnel-resonant diode.
}

Keywords: self-oscillator, tunneling resonant diode, negative differential resistance, frequency, quantum heterostructure

\section{BADANIA MAGNETYCZNEGO CZUJNIKA POLA Z SYGNALEM WYJŚCIOWYM CZĘSTOTLIWOŚCIOWYM W OPARCIU O DIODĘ TUNELOWO-REZONANSOWĄ}

\begin{abstract}
Streszczenie. Na podstawie uwzględnienia procesów fizycznych zachodzacych $w$ diodzie tunelowo-rezonansowej pod działaniem pola magnetycznego proponuje się skonstruowanie autogeneracyjnego czujnika pola magnetycznego o częstotliwościowym sygnale wyjściowym. Zastosowanie urządzeń o ujemnej rezystancji różnicowej pozwala znacznie uprościć konstrukcję czujników pola magnetycznego w całym zakresie częstotliwości RF. W zależności od trybu pracy czujnika sygnat wyjściowy można uzyskać w postaci oscylacji harmonicznych, a także w postaci oscylacji impulsów o specjalnej postaci.
\end{abstract}

Badanie charakterystyk czujnika pola magnetycznego opiera się na petnym obwodzie zastępczym tunelowej diody rezonansowej. Obwód zastępczy uwzględnia zarówno właściwości pojemnościowe, jak i indukcyjne tunelowej diody rezonansowej. Sktadowa indukcyjna istnieje w każdych warunkach pracy, na skutek tego, że prąd przeplywający przez urządzenie jest zawsze opóźniony w stosunku do napięcia, które go spowodowało, co odpowiada odpowiedzi indukcyjnej diody tunelowo-rezonansowej.

Słowa kluczowe: samoscylator, tunelowa dioda rezonansowa, ujemna rezystancja różnicowa, częstotliwość, heterostruktura kwantowa

\section{Introduction}

The characteristics of sensors determine the accuracy and reliability of control systems and regulation of devices for monitoring technological processes, environmental characteristics, the safety of industrial installations, and so on. Therefore, strict requirements are imposed on magnetic field sensors. They should be economical, ensure high measurement accuracy, have minimal dimensions, weight and power consumption, be compatible with modern computers and be able to be manufactured using standard integral technology $[8,14,19]$.

At present, the existing semiconductor magnetic field sensors do not satisfy the above requirements. They have a low output signal, low accuracy and sensitivity, and require analog-to-digital converters and amplifying devices for further signal processing. A promising scientific direction, eliminating the shortcomings of existing analog magnetic field sensors, is the creation of sensors that implement the principle of transformation "magnetic field induction - frequency" based on self-generated nanoelectronic structures with negative differential resistance. Tunneling resonance diodes belong to such nanoelectronic structures. The operation of these devices is based on the effect of electron tunneling through quantum heterostructures as they move perpendicularly to the plane of potential barriers separating quantum heterostructures.

\section{Formulation of the problem}

The theoretical foundations of the operation of tunnel resonance diodes were laid by L. Esaki and R. Tzu [6, 7, 23]. Indeed, in these works, they were the first to investigate the negative differential resistance in $\mathrm{AlGaAs} / \mathrm{GaAs}$ nanostructures as a result of resonant electron tunneling through potential barriers. The unique properties of tunnel-resonant diodes are their microwave properties together with negative differential resistance, which made it possible to build logic devices, memory devices, switches, resonant amplifiers, generators, sensors and many other devices on their basis [15-18].
The influence of the magnetic field on the characteristics of tunneling-resonant diodes was investigated in a number of works $[1,9,10]$, while the diodes acted as analog magnetic field sensors, however, the development and creation of magnetic field sensors with a frequency output signal has hardly been studied. Therefore, this work is devoted to the development of a mathematical model of a magnetic field sensor with a frequency output signal based on a tunnel resonance diode, which made it possible to obtain the main characteristics of the sensor.

\section{Theoretical research}

Before proceeding to the consideration of the mathematical model of the magnetic field sensor based on a tunnel-resonant diode, we need to briefly consider its structure, energy diagram, the density of electronic states and its dependence on the electron energy, current-voltage characteristic, the transparency coefficient of potential barriers on the energy of electrons tunneling through these barriers. This knowledge is necessary for the development of a mathematical model and the possibility of using it as a magnetic field sensor with a frequency output.

The classical structure of a tunnel-resonant diode, which is a two-dimensional semiconductor quantum heterostructure, consists of a nanometer-length GaAs gallium arsenide film, on which a nanometer-sized layer of gallium arsenide aluminate $\mathrm{AlGaAs}$ with a wider band gap is deposited on both sides. When $x=0.3$, the band gap of $\mathrm{Al}_{\mathrm{x}} \mathrm{Ga}_{1-\mathrm{x}} \mathrm{As}$ is approximately $2 \mathrm{eV}$, while for $\mathrm{GaAs}$, it is $1.4 \mathrm{eV}$. This leads to the fact that a potential barrier with an almost rectangular shape and a height of $0.4 \mathrm{eV}$ for electrons and $0.2 \mathrm{eV}$ for holes arises as a result of the rupture of the bottom of the conduction band and the top of the valence band. On one side and the other, gallium arsenide aluminate is sprayed with $n+-$ GaAs serving as an emitter and a collector; and all film layers are located on a GaAs substrate [22]. From an energy point of view, the conduction band of a tunneling-resonant diode has two potential barriers, between which a quantum well is located (Fig. 1a) [5]. This structure of the diode is called a two-barrier 
heterojunction nanostructure. As a result, electrons from the emitter region need to tunnel through barriers and a quantum well to get into the reservoir area when they move perpendicular to the walls of the barrier. The motion of electrons in the quantum well is limited by the direction of the $\mathrm{z}$ coordinate, while in the plane ( $\mathrm{x}, \mathrm{y})$ they are free and their behavior is the same as in threedimensional semiconductor bodies (Fig. 1b) [5].

In this case, the wave function of an electron can be represented as a product of wave functions in coordinates $\mathrm{x}, \mathrm{y}, \mathrm{z}$ $[3,12]$.

$$
\psi=\psi_{x} \psi_{y} \psi_{z}
$$

where $\psi(x)$ and $\psi(y)$ are solutions to the Schrödinger equation for a free electron, that is, they describe a traveling wave. At the same time, the wave function $\psi(z)$ is a solution of the same Schrödinger equation only for an electron in a rectangular potential well $U(z)$ [12].

$$
\psi(z)=\left(\frac{2}{a}\right)^{2} \sin \left(\frac{\pi n z}{a}\right), \quad n=(1,2, \ldots)
$$

where $a$ is the width of the potential well.

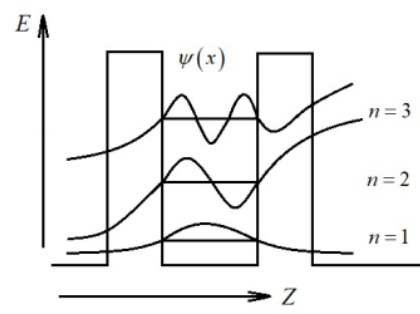

a)

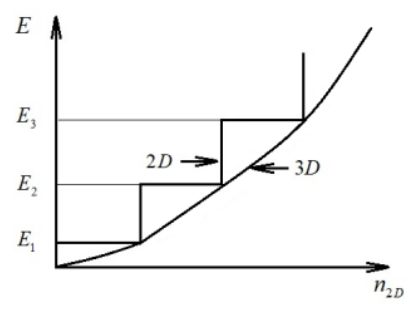

b)
Fig. 1. Schematic representation of the energy diagram of the conduction band of a tunnel-resonant diode with three energy levels and a change in the wave function with different electron energies (a); dependence of the density of quantum states on the electron energy for quantum two-dimensional and classical three-dimensional structures (b) [5]

The total energy of an electron in a potential well is described by the expression [12]:

$$
\begin{aligned}
& E\left(K_{x}, K_{y}, n\right)=\frac{\hbar^{2}}{2 m^{*}}\left(K_{x}^{2}+K_{y}^{2}\right)+E_{n}= \\
& =\frac{\hbar^{2}}{2 m^{*}}\left(K_{x}^{2}+K_{y}^{2}\right)+\frac{\pi^{2} \hbar^{2}}{2 m^{*} a^{2}} n^{2}, \quad n=(1,2 \ldots)
\end{aligned}
$$

where $\hbar=h / 2 \pi$ is Planck's constant; $m^{*}$ is the effective mass of an electron; $K_{x}, K_{y}$ are projections of the wave vector of electrons on the $\mathrm{x}$ and $\mathrm{y}$ axes; $E_{n}$ is the energy levels in a quantum well; and $n$ is the number of energy levels in the quantum well.

In Fig. 1b, a graph of the function of the density of states versus the change in the energy of electrons is shown, from which it can be seen that the function has a stepwise character, with all of the steps having the same width, but located at discrete values of energy $E_{n}$. Based on Fig. 1b, we can say that energy values between 0 and $E_{1}$ are prohibited. In the energy range $E_{1}<E<E_{2}$, electrons can be located in the subband, which corresponds to $n=1$. Two subzones can be located simultaneously in the energy range between $E_{1}$ and $E_{2}$, according to $n=1$ and $n=2$.
This leads to the fact that the density of the states function doubles in value. In general, it is described by the formula [5]:

$$
n_{2 D}(E)=\frac{m^{*}}{\pi \hbar^{2} a} \sum_{n} \theta\left(E-E_{n}\right), \quad n=(1,2, \ldots)
$$

where $\theta\left(E-E_{n}\right)$ is a step function; $\hbar=(h / 2 \pi)$. The solid line in Fig. $1 \mathrm{~b}$ is a parabolic curve for the three-dimensional case, which shows the difference between two-dimensional and threedimensional systems. This difference is more pronounced at small values of the quantity $n$.

To obtain the current-voltage characteristics of the tunnelresonant diode, the Schrödinger equation is used in the general form [21]:

$$
-\frac{\hbar^{2}}{2 m^{*}} \frac{\partial^{2} \psi_{n}}{\partial \vec{r}^{2}}+U(\vec{r}) \psi_{n}(\vec{r})=E(\vec{K}) \psi_{n}(\vec{r})-E_{n}(0) \psi_{n}(\vec{r})
$$

where $\psi_{n}(\vec{r})$ is the wave function of an electron, which depends on the radius vector $\vec{r}$, which corresponds to an electron with energy level $n ; U(\vec{r})$ - potential energy of barriers; $\vec{K}$ - wave vector of the electron; $E(\vec{K})$ - electron energy; $E_{n}(0)$ - energy of an electron in a quantum well at $K=0$ when the energy of the resonance level $E_{0}$ is equal to the bottom of the conduction band $E_{c}$. Based on equation (5), a function of the current density of the applied voltage is obtained, which is called the Ttsu-Esaki function $[2,4,23]$

$$
J=\frac{q m^{*} k T}{2 \pi^{2} \hbar^{3}} \int_{E_{C}}^{\infty} T\left(E_{Z}\right) \log \left[\frac{1+\exp \left(\frac{E_{F}-E_{Z}}{k T}\right)}{1+\exp \left(\frac{E_{F}-E_{Z}-q U}{k T}\right)}\right] d E_{Z}(6)
$$

where $k$ is Boltzmann constant; $T$ - absolute temperature; $E_{F}-$ Fermi level in the conduction band of the emitter; $U$ - applied voltage; $T\left(E_{Z}\right)$ - transparency coefficient of electrons passing through potential barriers and a quantum well.

For a more accurate description of the current-voltage characteristic, it is necessary to take into account the phonon scattering of electrons, scattering by impurities, scattering at layer boundaries, and scattering of electrons by alloys. A numerical kinetic model based on Green's functions [21] most accurately describes the current-voltage characteristic of tunneling-resonant diodes. One of the problems in calculating the current-voltage characteristic is the determination of the transparency coefficient $T\left(E_{Z}\right)$ two-barrier quantum heterostructure.

The transparency coefficient of a potential barrier is understood as the ratio of the flux density of electrons passing through the barrier to the electron flux density of the incident wave. The coefficient of reflection of electrons from the barrier is determined by the ratio of the flux density of reflected electrons from the barrier to the flux density of electrons incident on the barrier. Let us consider the case when electrons interact with a rectangular potential barrier of width $a$ whose height $U(z)$ is more energy $E$ electrons $(U(z)>E)$. In this case, the transparency coefficient $T(E)$ is described by the expression $[5,11]$ :

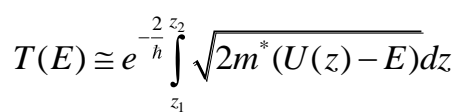


where $z_{1}$ and $z_{2}$ are turning points in the condition $E=U\left(z_{1}\right)=U\left(z_{2}\right)$. Reflection coefficient $R(E)$ in this case is determined based on the relation $R(E)=1-T(E)$.

The situation changes significantly in the process of tunneling electrons through the double barrier when the function $T(E)$ takes on a more complex form and is a product of two quantities: $T_{E}$ for the first barrier or emitter, and $T_{K}$ for a second barrier or collector:

$$
T(E)=T_{E} \cdot T_{K}
$$

The problem is solved most easily when the barriers are identical. The coefficient of such a two-barrier structure is described by the equation [12]:

$$
T(E)=\frac{T_{0}^{2}}{T_{0}^{2}+4 R_{0} \cos ^{2}(\xi a-Q)}
$$

where the values $T_{0}$ and $R_{0}-$ transparency and reflection coefficients for a single barrier; $\xi=1 / \hbar \sqrt{2 m^{*}\left(U_{0}-E\right)}$; and $Q-$ a phase angle.

Let us proceed to consider the influence of the magnetic field on the parameters of the tunnel-resonant diode. In bulk $3 \mathrm{D}$ crystals under the influence of magnetic field $B$, the electron energy quantum is only in the plane perpendicular to $B$, however, in two-dimensional electronic systems, the energy spectrum can be quantized completely. This idea is based on the solution of the Schrödinger equation for electrons in such a system when a magnetic field is applied to it, which is directed along the $z$ axis perpendicular to the plane of the system. The Schrödinger equation for the wave function $\psi(r)=\psi(x, y)$ two-dimensional system takes the form [12]:

$$
\left[-\frac{\hbar^{2}}{2 m^{*}} \frac{\partial^{2}}{\partial x^{2}}+\frac{1}{2 m^{*}}\left(i \hbar \frac{\partial}{\partial y}+q B x\right)^{2}\right] \psi(x, y)=E \psi(x, y)
$$

where $q$-electron charge; $B$ - magnetic induction; and $E$ - the energy of electrons. After transformations in square brackets, the equation takes the form:

$$
\left[-\frac{\hbar^{2}}{2 m^{*}}\left(\frac{\partial^{2}}{\partial x^{2}}+\frac{\partial^{2}}{\partial y^{2}}\right)-\frac{i \hbar q B x}{m^{*}}-\frac{(q B x)^{2}}{2 m^{*}}\right] \psi(x, y)=E \psi(x, y)(11)
$$

The solution to equation (11) is presented in the form [12]:

$$
\psi(x, y)=\varphi(x) e^{i K y}
$$

where the plane wave corresponds to the coordinate $y$. Substituting expression (12) into equation (11), we obtain an equation for the functional dependence on coordinate $x$ in the form [12]:

$$
\left[-\frac{\hbar^{2}}{2 m^{*}} \frac{d^{2}}{d x^{2}}+\frac{1}{2} m^{*} \omega_{c}^{2}\left(x-x_{0}^{2}\right)\right] \psi(x)=E \psi(x)
$$

where the value $\omega_{c}$ equals:

$$
\omega_{c}=\frac{q B}{m^{*}}
$$

and $x_{0}$ has the form [12]:

$$
x_{0}=\frac{h K}{q B}
$$

Expression (13) is the Schrödinger equation for a onedimensional harmonic oscillator, since the application of $x_{0}$ to $x$ means the shift of the center of the parabolic potential by the amount $x_{0}$, so the parameter $x_{0}$ called the center of coordinates.

Thus, the solution of equation (13) provides an important result, which shows that the eigenstates of a two-dimensional system in a magnetic field are determined by the expression [12]:

$$
E_{n}=\left(N+\frac{1}{2}\right) \hbar \omega_{C}, \quad N=0,1,2 \ldots
$$

where $N$ is the Landau levels.

The obtained energy values depend on quantum number $N$ and the magnitude of magnetic field $B$ through cyclotron frequency $\omega_{c}$.

Thus, we can conclude that in strong magnetic fields, which are directed perpendicular to the plane of a two-dimensional quantum heterostructure, electrons move along cyclotron orbitals with frequency $\omega_{c}$, which is determined by equation (14). Moreover, their energy is quantized according to the rules of a harmonious quantum oscillator. It follows from the above that the function of the density of states of a two-dimensional electron gas after the application of magnetic field $B$ for each of the Landau levels turns into an $\delta$-function. Fig. 2 shows that the lowest of the Landau levels corresponds to the energy $h \omega_{c} / 2$, and it lies above the bottom of the parabolic zone. Due to the scattering of electrons by impurities, the lines broaden, blurring $\delta$ - functions, as shown in Fig. 2 [12].

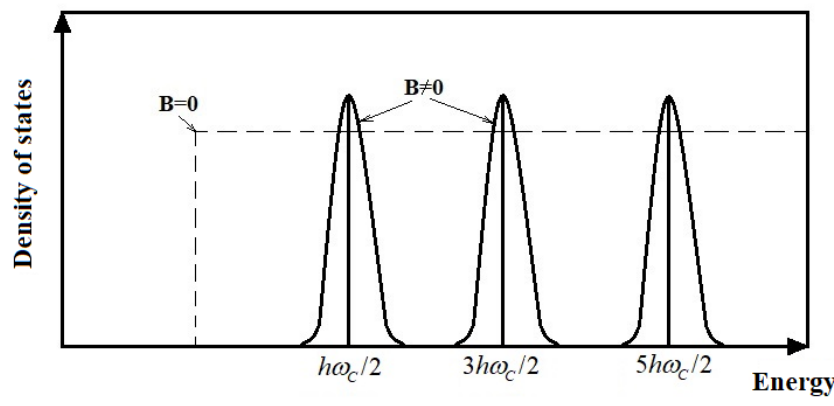

Fig. 2. Dependence of the function of the density of states of a two-dimensional electron gas on the energy in a magnetic field; for comparison, similar dependences are presented for a two-dimensional system at $B=0$ [12]

After the application of magnetic field $B$, all Landau levels in energy range $h \omega_{c}$ turn into one common Landau level. In this case, degeneracy coefficient $D$ of the Landau levels is described by the expression [12]:

$$
D=\frac{q B}{2 \pi h}
$$

As can be seen from formula (17), the degeneracy of the Landau levels increases linearly with the applied magnetic field. The allowed energy levels, when the magnetic field is perpendicular to the two-dimensional system, lie on concentric circles with a constant radius $K^{2}=K_{x}^{2}+K_{y}^{2}=(2 q B / \hbar)(N+1 / 2)$. 
Thus, the kinetic energy of an electron in a quantum well is [21]:

$$
E_{R, n}=E_{R}(U)+\left(N+\frac{1}{2}\right) \hbar \omega_{c} \pm g^{*} \mu B
$$

where $E_{R}(U)$ - energy of electrons, which depends on the applied voltage $U ; g^{*} \mu B$ - magnetic energy of the electron spin; $\mu$ - electron mobility; $B$ - magnetic induction; and $g^{*}$ - Lande coefficient $[13,21,24]$.

Let us move on to considering the mathematical model of a magnetic field sensor with a frequency output based on a tunnel-resonant diode. The main characteristic of such a device is the dependence of the resonant frequency of a generator built on a diode, from the measured value, in our case, the magnetic induction. This dependence can be determined based on the electrical circuit of the sensor, which is shown in Fig. 3.

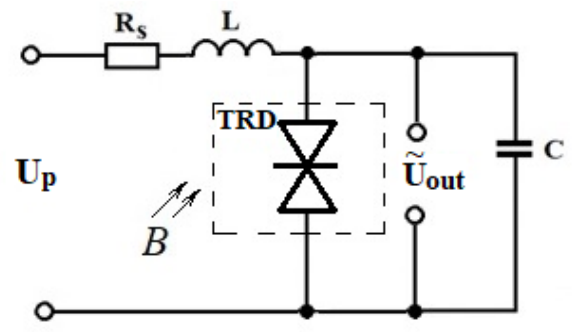

Fig. 3. Electrical diagram of a magnetic field sensor

In the tunnel-resonant diode, the current-voltage characteristic has a falling section corresponding to the existence of a differential negative resistance in this section. The descending section arises due to a decrease in the current that passes through the double-barrier quantum heterostructure due to a decrease in the transparency coefficient of potential barriers due to an increase in the energy of tunneling electrons with increasing voltage and the action of a magnetic field in comparison with the energy resonance level. The negative differential resistance converts the DC electric field energy of the tunnel-resonant diode power supply into AC electric field energy. The electrical circuit of the sensor (Fig. 3) is powered from constant voltage source $U_{P}$. Loss resistance $R_{S}$, which includes all of the ohmic resistances of the circuit, external inductance $L$, which is connected in series to the internal inductance of the diode, and also contains the inductance of the circuit terminals, external capacitance $C$, which is connected in parallel to the internal capacitance of the diode, as well as the tunnel-resonant diode itself, on which the magnetic field acts.

An equivalent sensor circuit for calculating its characteristics is presented in Fig. 4.

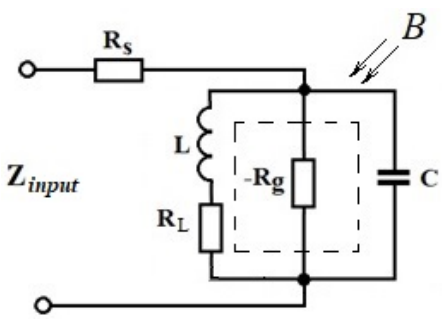

Fig. 4. Equivalent circuit of a magnetic field sensor

Power source $I(U)$ at the operating point on the descending section of the current-voltage characteristic determined the ratio $U / I(U)$, which corresponds to negative differential resistance $R_{g}$ (Fig. 4).
Based on the equivalent circuit (Fig. 4), we calculate input impedance $Z_{\text {input }}$, on the basis of which we determine the resonant frequency. The impedance is expressed as:

$Z_{\text {input }}=R_{s}+\frac{\left[\frac{R_{g}}{1+\left(\omega C R_{g}\right)^{2}}\right]^{2} R_{L}+\left[\frac{R_{g}}{1+\left(\omega C R_{g}\right)^{2}}\right](\omega L)^{2}}{\left[\frac{R_{g}}{1+\left(\omega C R_{g}\right)^{2}}+R_{L}\right]^{2}+\left[\omega L-\frac{\omega C R_{g}^{2}}{1+\left(\omega C R_{g}\right)^{2}}\right]^{2}}+$

$+\frac{\left[\frac{\omega C R_{g}^{2}}{1+\left(\omega C R_{g}\right)^{2}}\right]^{2} R_{L}+\left[\frac{R_{g}}{1+\left(\omega C R_{g}\right)^{2}}\right] R_{L}^{2}}{\left[\frac{R_{g}}{1+\left(\omega C R_{g}\right)^{2}}+R_{L}\right]^{2}+\left[\omega L-\frac{\omega C R_{g}^{2}}{1+\left(\omega C R_{g}\right)^{2}}\right]^{2}}+$

$+j \frac{\left[\frac{R_{g}}{1+\left(\omega C R_{g}\right)^{2}}\right]^{2}(\omega L)-\left[\frac{\omega C R_{g}^{2}}{1+\left(\omega C R_{g}\right)^{2}}\right] R_{L}^{2}}{\left[\frac{R_{g}}{1+\left(\omega C R_{g}\right)^{2}}+R_{L}\right]^{2}+\left[\omega L-\frac{\omega C R_{g}^{2}}{1+\left(\omega C R_{g}\right)^{2}}\right]^{2}}+$

$+j \frac{-\left[\frac{\omega C R_{g}^{2}}{1+\left(\omega C R_{g}\right)^{2}}\right](\omega L)^{2}+\left[\frac{\omega C R_{g}^{2}}{1+\left(\omega C R_{g}\right)^{2}}\right]^{2}(\omega L)}{\left[\frac{R_{g}}{1+\left(\omega C R_{g}\right)^{2}}+R_{L}\right]^{2}+\left[\omega L-\frac{\omega C R_{g}^{2}}{1+\left(\omega C R_{g}\right)^{2}}\right]^{2}}$.

Let us equate to zero the imaginary component of Eq. (19) and determine resonant frequency $f_{\text {res }}$, which is described by the formula:

$$
\begin{aligned}
& \omega^{4}\left[R_{g}^{4}(B) C^{3} L^{2}\right]+ \\
& +\omega^{2}\left[C^{3} R_{g}^{4}(B) R_{L}^{2}+C R_{g}^{2}(B) L^{2}-R_{g}^{4}(B) C^{2} L\right]+ \\
& +\left[C R_{g}^{2}(B) R_{L}^{2}-R_{g}^{2}(B) L\right]=0
\end{aligned}
$$

The solution to equation (20) is the expression:

$$
f_{r e s}=\frac{1}{2 \pi} \sqrt{\frac{C^{3} R_{g}^{4}(B) R_{L}^{2}+C R_{g}^{2}(B) L^{2}-R_{g}^{4}(B) C^{2} L+A}{2 C^{3} R_{g}^{4}(B) L^{2}}}
$$

where:

$$
\begin{aligned}
& A=\operatorname{sqrt}\left[\left(C^{3} R_{g}^{4}(B) R_{L}^{2}+C R_{g}^{2}(B) L^{2}-R_{g}^{4}(B) C^{2} L\right)^{2}-\right. \\
& \left.-4 C^{3} R_{g}^{4}(B) L^{2}\left(C R_{g}^{2}(B) R_{L}^{2}-R_{g}^{2}(B) L\right)\right]
\end{aligned}
$$

\section{Experimental research}

When a magnetic field is applied to a tunnel-resonant diode, in the direction parallel to the current, a change in the energy of the electrons tunneling through potential barriers occurs, leading to a change in the current through the device. The change in current causes a change in the negative differential resistance, which in turn uniquely changes the resonant frequency. The change in the intrinsic capacitance and inductance of the diode is four orders of magnitude less in relation to the values of the external capacitance and inductance, therefore, their effect on the resonant frequency can be ignored [20, 25]. 
Fig. 5 shows the theoretical and experimental dependences of the resonant frequency, that is, the sensor conversion function on the action of the magnetic field. As can be seen from Fig. 5 , the conversion function increases with an increase in the magnetic field induction while maintaining a constant sensor supply voltage. This is due to the fact that the main contribution to the frequency change is made by the component of the change in the electron energy according to the law $\left(N+\frac{1}{2}\right) h \omega_{c}$, that is, the energies of the cyclotron orbitals of electron motion.

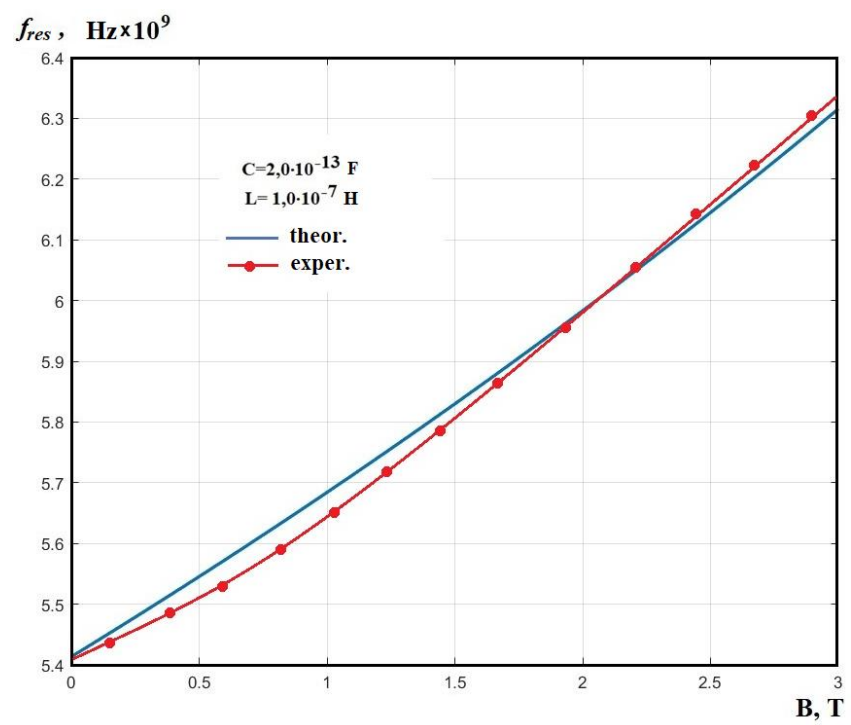

Fig. 5. Theoretical and experimental dependence of the sensor conversion function on the action of the magnetic field

The sensitivity of the magnetic field sensor is determined by the first derivative of the conversion function with respect to magnetic induction, that is, equal to the ratio $\mathrm{kHz} / \mathrm{mT}$. Fig. 6 shows the theoretical dependence of the sensor sensitivity function on the action of the magnetic field, its analytical expression is a complex expression and is described by the equation:

$$
\begin{aligned}
& S_{B}=0.0562687 \cdot\left(\frac { 1 } { C ^ { 3 } R _ { g } ^ { 3 } ( B ) R _ { L } ^ { 2 } } \left(4 C^{3} R_{g}^{3}(B) R_{L}^{2}\left(\frac{\partial R_{g}(B)}{\partial B}\right)+\right.\right. \\
& +2 C R_{g}(B) L^{2}\left(\frac{\partial R_{g}(B)}{\partial B}\right)-4 R_{g}^{3}(B) C^{2} L\left(\frac{\partial R_{g}(B)}{\partial B}\right)+ \\
& +\frac{1}{2}\left(2\left(C^{3} R_{g}^{4}(B) R_{L}^{2}+C R_{g}^{2}(B) L^{2}-R_{g}^{4}(B) C^{2} L\right) \times\right. \\
& \times\left(4 C^{3} R_{g}^{3}(B) R_{L}^{2}\left(\frac{\partial R_{g}(B)}{\partial B}\right)+2 C R_{g}(B) L^{2}\left(\frac{\partial R_{g}(B)}{\partial B}\right)-\right. \\
& \left.-4 R_{g}^{3}(B) C^{2} L\left(\frac{\partial R_{g}(B)}{\partial B}\right)\right)-16 C^{3} R_{g}^{3}(B) L^{2} \times \\
& \times\left(C R_{g}^{2}(B) R_{L}^{2}-R_{g}^{2}(B) L\right)\left(\frac{\partial R_{g}(B)}{\partial B}\right)-4 C^{3} R_{g}^{4}(B) L^{2} \times \\
& \left.\left.\times\left(2 C R_{g}(B) R_{L}^{2}\left(\frac{\partial R_{g}(B)}{\partial B}\right)-2 R_{g}(B) L\left(\frac{\partial R_{g}(B)}{\partial B}\right)\right)\right) / A\right)- \\
& -\frac{1}{C^{3} R_{g}^{5}(B) L^{2}}\left(4 \left(C^{3} R_{g}^{4}(B) R_{L}{ }^{2}+C R_{g}^{2}(B) L^{2}-R_{g}^{4}(B) C^{2} L \times A \times\right.\right. \\
& \left.\left.\left.\times\left(\frac{\partial R_{g}(B)}{\partial B}\right)\right)\right)\right) / \sqrt{\frac{C^{3} R_{g}^{4}(B) R_{L}{ }^{2}+C R_{g}^{2}(B) L^{2}-R_{g}^{4}(B) C^{2} L+A}{C^{3} R_{g}^{4}(B) L^{2}}}
\end{aligned}
$$

As can be seen from the graph (Fig. 6), the sensitivity value varies from $250 \mathrm{kHz} / \mathrm{mT}$ to $300 \mathrm{kHz} / \mathrm{mT}$, the optimal area, when the change in the sensitivity function is only $10 \mathrm{kHz} / \mathrm{mT}$, is the range of magnetic field induction change from $1 \mathrm{~T}$ to $3 \mathrm{~T}$. The complex nature of the behavior of the sensitivity function on the magnetic field is explained by the complex dependence of the sensor conversion function on the change in negative differential resistance when a magnetic field is applied.

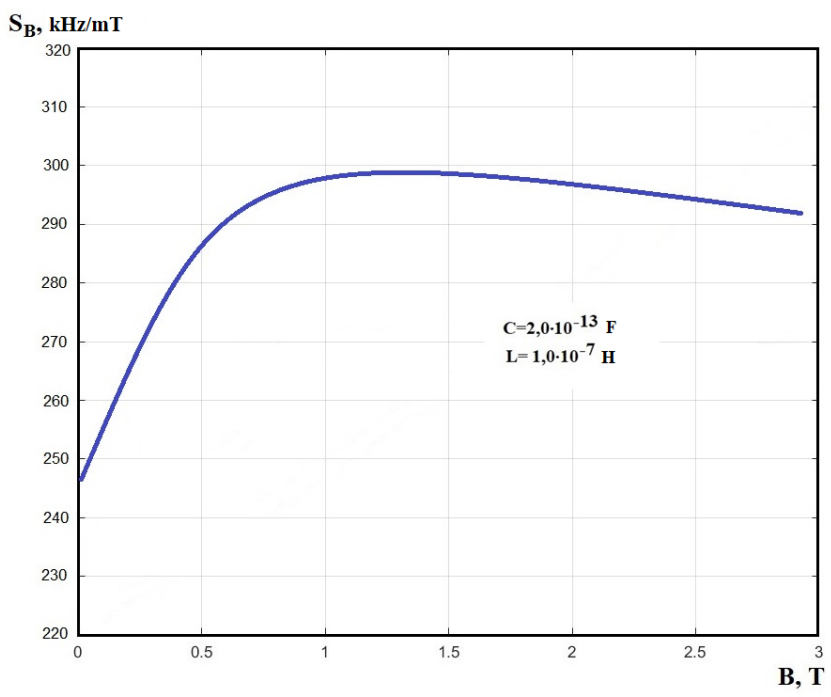

Fig. 6. Dependence of the sensitivity of the sensor on the action of the magnetic field

\section{Conclusions}

1) A mathematical model of a magnetic field sensor has been developed, with which the analytical dependences of the conversion and sensitivity functions are determined. It is shown that the main contribution to the conversion function is made by the change in the energy of electrons during their motion in cyclotron orbitals under the influence of a magnetic field. It changes the negative differential resistance, which in turn changes the output frequency of the magnetic sensor. The sensitivity of the magnetic field sensor varies from $250 \mathrm{kHz} / \mathrm{mT}$ to $300 \mathrm{kHz} / \mathrm{mT}$ in the range of magnetic field induction from zero to 3 Tesla. In this case, the output frequency varied from $5.4 \cdot 10^{9} \mathrm{~Hz}$ to $6.3 \cdot 10^{9} \mathrm{~Hz}$.

2) Based on the consideration of physical processes in a tunnelresonant diode under the influence of a magnetic field, it is proposed to design magnetic field sensors with a frequency output signal. These sensors have significant advantages over analog magnetic field sensors. Their advantages are the ability to operate in the microwave range, increasing the microminiaturization of the sensor down to the nanoscale, the ability to measure magnetic induction from tens of millitesla to tens of tesla with wireless transmission of the measured information over a distance.

\section{References}

[1] Awan J. T.: Optical and Transport of pin GaAs-AlAs resonant tunneling diode UFS Car 2014.

[2] Azarov O. D., Garnaga V. A.: Push-pull DC amplifiers for multi-bit converters of self-calibrating information. Universum, Vinnytsia 2011

[3] Azarov O. D., Krupelnytsky L. V.: Analog-digital devices of self-correcting systems for measurement and processing of low-frequency signals. Universum, Vinnytsia 2005.

[4] Azarov O. D., Teplitsky M. Yu., Bilichenko N. O.: High-speed push-pull DC amplifiers with balanced feedback. VNTU, Vinnytsia 2016.

[5] Borisenko V. E. et al.: Nanoelectronics: theory and practice textbook. Binom. Knowledge Laboratory, Moscow 2013.

[6] Chand L. L., Esaki L., Tsu R.: Resonant tunneling in semiconductor double barriers. Appl. Phys. Lett. 24, 1974, 593-595.

[7] Esaki L., Tsu R.: Superlattics and negative differential conductivity in semiconductors. IBM J. Res. Develop. 14/1970, 61-65.

[8] Gotra S.Yu.: Microelectronic sensors of physical quantities. League - press, Lviv 2020. 
[9] Halimatus S., Warsuzarina M., Nabihah A., Jabbar M.: Resonant Tunneling Diode Design for Oscillator Circuit. International Postoraduate Conference Physics, 2017, 1-8.

[10] Huber J. L.: Physics of Novel InAs / AlSb / GaSb Resonant Interband Tunneling Structures. A Dissertation in Candidacy for the Degree of Doctor of Philosophy. Yale University, USA 1997.

[11] Karandakov G. V., Kryvenko V. I.: Electrical engineering, electronics and microprocessor technology. NTU, Kyiv 2008.

[12] Martinez-Duart J. M. et al.: Nanotechnology for micro- and optoelectronics. Technosphere, Moscow 2009

[13] McCarthy M., Collins A.: Switches and Multiplexers. Analog Dialogue 31(3), 1997, 20-22.

[14] Meizda F.: Electronic measuring instruments and measurement methods. Mir, Moscow 1990.

[15] Osadchuk I. A., Osadchuk A. V., Osadchuk V. S., Semenov A. O.: Nanoelectronic Pressure Transducer with a Frequency Output Based on a Resonance Tunnel Diode. 2020 IEEE 15th International Conference on Advanced Trends in Radioelectronics, Telecommunications and Computer Engineering (TCSET), Lviv-Slavske, Ukraine 2020, 452-457, [http://doi.org/10.1109/TCSET49122.2020.235474].

[16] Osadchuk V. S., Osadchuk A. V.: Radiomeasuring Microelectronic Transducers of Physical Quantities. Proceedings of the 2015 International Siberian Conference on Control and Communications (SIBCON), Omsk 2015 [http://doi.org/10.1109/SIBCON.2015.7147167].

\section{Prof. Alexander Osadchuk}

e-mail: osadchuk.av69@gmail.com

Doctor of Technical Sciences, Professor, Head of the Department Radio Engineering of Vinnitsa National Technical University, Academician of the Academy Metrology Ukraine. Author of over 850 publications, including 30 monographs, 15 textbooks, 280 patents for inventions in Ukraine and the Russian Federation, more than 500 scientific articles in professional journals, of which 56 are in the scientometric databases Scopus and Web of Science.

https://orcid.org/0000-0001-6662-9141

\section{Prof. Vladimir Osadchuk}

e-mail: osadchuk.vs38@gmail.com

Doctor of Technical Sciences, Professor, Professor of the Department Radio Engineering of Vinnitsa National Technical University, Honored Worker of Science and Technology of Ukraine, Academician of the Academy of Engineering Sciences of Ukraine. Author of more than 900 publications, including 22 monographs, 14 textbooks, more than 350 copyright certificates and patents for inventions and more than 550 scientific articles in professional journals, of which 35 are in scientometric databases Scopus and Web of Science.
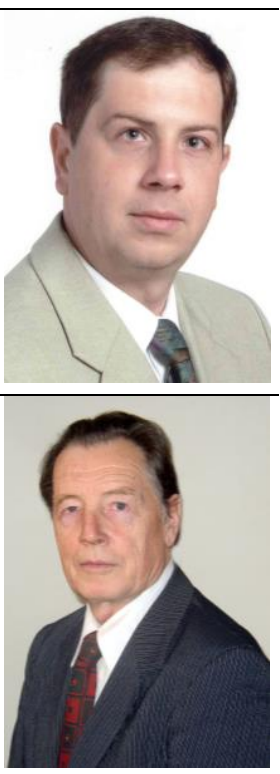

[17] Osadchuk V. S., Osadchuk A. V., Osadchuk I. A.: Microelectronic pressure transducer with frequency output based on tunnel resonance diode. Bulletin of Khmelnytsky National University - Technical science 1, 2015, 97-101.

[18] Osadchuk V.S., Osadchuk A. V.: The Microelectronic Radiomeasuring Transducers of Magnetic Field with a Frequency Output. Elektronika ir Elektrotechnika 4, 2011, 67-70 [http://doi.org/10.5755/j01.eee.110.4.289].

[19] Osadchuk V.S., Osadchuk A.V.: Microelectronic sensors of magnetic field with frequency output. Universum, Vinnitsa 2013.

[20] Romanyuk N. et al.: Microfacet distribution function for physically based bidirectional reflectance distribution functions. Proc. SPIE 8698, 86980L [http://doi.org/10.1117/12.2019338].

[21] Sun J. P., Haddad G. J. et al.: Resonant Tunneling Diodes: Models and Properties. Proceedings of The IEEE 86(4), 1998, 641-661.

[22] Sze S. M., Kwok K. Ng.: Physics of Semiconductor Devices. Wiley-Interscience 2007.

[23] Tsu R., Esaki L.: Tunneling in a finite superlattice. Appl. Phys. Lett. 22, 1973, $562-564$.

[24] Vasilevskyi O. M., Yakovlev M. Y., Kulakov P. I.: Spectral method to evaluate the uncertainty of dynamic measurements. Technical Electrodynamics 4, 2017 , 72-78.

[25] Vasilevskyi O. M.: Methods of determining the recalibration interval measurement tools based on the concept of uncertainty. Technical Electrodynamics 6, 2014, 81-88.

\section{Associate Professor Iaroslav Osadchuk}

e-mail: osadchuk.j931@gmail.com

Candidate of Technical Sciences, Associate Professor of the Department Radio Engineering, Vinnytsia National Technical University. Author of more than 150 publications, including 4 monographs, 50 patents for inventions and more than 100 scientific articles in professional journals, of which 19 are in scientometric databases Scopus and Web of Science.

https://orcid.org/0000-0002-5472-0797

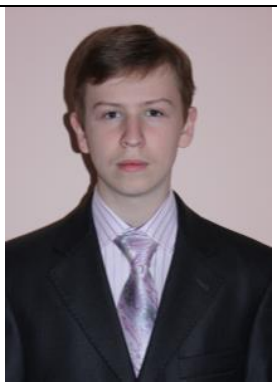

otrzymano/received: 08.10.2020 przyjęto do druku/accepted: 10.12 .2020 